by natural catastrophes such as fire or wind-blow, numbers inevitably rise. Some control of weevil increase is afforded by insect parasites, such as Bracon hylobii Ratz. and Ephialtes tuberculatus Geoff. in Four., by fungal attack on larvæ and possibly by birds. Generally, this natural control is unable to keep populations below a density at which they can cause serious damage to young conifer crops.

\section{The Nucleus in a Basidiomycete}

A. Bakerspiget has given a detailed account, with numerous photographic illustrations, of the structure and manner of division of vegetative hyphal nuclei in Schizophyllum commune (Canad. J. Bot., 37, No. 5,$835 ; 1959)$. These nuclei do not divide in a manner directly comparable to ordinary mitosis. During division the tightly packed chromatinic granules become loosely arranged, after which they contract into a densely stained bar. As division proceeds, this bar of chromatin elongates and then constricts at its mid-region. At the end of division the extremities pull apart quickly to form the chromatin portions of the two sister nuclei. The Feulgen-negative central bodies decrease in size, and at the end of division their remnants lie free in the cytoplasm. New central bodies arise in the maturing sister nuclei. Throughout division, metaphase plates, spindles, or individual chromosomes were not observed in any of the stained or living preparations. A nuclear membrane has not been observed surrounding any of these nuclei.

\section{Anchiceratops from Alberta}

A Natural history paper by Mr. Wann Langston, jun. (No. 3; September 23, 1959), published by the National Museum of Canada, deals with specimens of Anchiceratops from the Oldman formation of Alberta. This is an Upper Cretaceous bed, and the material was collected by a National Museum expedition of 1937. The paper describes fully the specimens in the Museum and discusses the habitat of Anchiceratops and the characteristics of the sediments in which they are found.

\section{Miniature Gyroscopes}

IN the first of a series of articles devoted to microinstruments, W. R. Simons of Smiths Aircraft Instruments Ltd., describes the use of miniature gyroscopes in aircraft and guided missiles (Research for Industry, 13, No. 2; February, 1960). The special requirements of guided missile control systems and recent developments in the design of aircraft auto-pilots have created a demand for miniaturized gyroscopes, possessing high accuracy together with exceptional reliability and robustness. Some of the fundamental problems associated with the design of these miniature gyroscopes are discussed and typical examples of the instruments are described.

\section{Bibliography on Plasma Physics and Magnetohydro- dynamics}

THOUGH the subject of magnetohydrodynamies dates back to the nineteenth century, it is primarily in the past two decades that it has attracted wide attention. Its importance, first recognized in astrophysics, has spread to many fields, particularly the study of the flow of gases and the appearance of ionization, and the phenomena presented by completely ionized plasmas at extremely high temperatures. The literature on the subject has increased a.t a rapid rate, and we are indebted to J. D. Ramer, of the Engineering and Physical Sciences Library of the University of Maryland, for the collection of literature of the period 1937-59 which he has compiled (Bibliography on Plasma Physics and Magnetohydrodynamics and their Applications to Controlled Thermonuclear Reactions. Pp. ii +105 . College Park, Maryland: Engineering and Physical Sciences Library, University of Maryland, 1959). The bibliography contains 1,707 references arranged alphabetically by authors. In general, the titles of the papers are given in English, but the language of the original article is quoted. The author index seems superfluous (it covers twelve pages), but together with the numerical index to Atomic Energy Reports (five pages) and the alphabetical list of journals referred to in the bibliography (four pages) which complete the volume, it gives an excellent impression of the wide and useful coverage of the bibliography.

\section{Scholarships in Chemical Engineering}

Constructors John Brown, Ltd., have entered into an agreement with the Institution of Chemical Engineers for the award of two scholarships. The purpose of the scholarships is to encourage research in chemical engineering and, in particular, in chemical plant design. The scholarships are tenable at any educational institution in the United Kingdom in receipt of grants from the University Grants Committee, and having a department of chemical engineering under the direction of a professor of chemicel engineering. Further information can be obtained from Dr. J. B. Brennan, Institution of Chemical Engineers, 16 Belgrave Square, London, S.W.I. Applications should reach the Institution not later than June 1.

\section{University News :}

Birmingham

THE following appointments to lectureships have been made: Dr. G. H. Burkhardt (mathematical physics); Dr. D. C. Champeney (physics); $\mathrm{Mr}$. D. A. O'Connor (physics); Dr. M. J. Lawrence (genetics); Mr. G. H. Trengrouse (mechanical engineering); and Mr. E. Amini (mechanical engineering).

Edinburgh

A CHAIR of electrical engineering has been instituted in the University of Edinburgh and applications for appointment to it will shortly be invited.

\section{London}

Dr. K. W. Cross, reader in physiology at St. Mary's Hospital Medical School, has been appointed to the University chair of physiology tenable at the London Hospital Medical College. Dr. B. C. L. Weeden, reader in organie chemistry at the Imperial College of Science and Technology, has been appointed to the University chair of organic chemistry tenable at Queen Mary College. Dr. D. V. Ager, lecturer in geology at the Imperial College of Science and Technology, has been appointed to the University readership in geology tenable at that College. The title of reader in the history and philosophy of science in the University of London has been conferred on Dr. N. H. de V. Heatheote in respect of his post at University College.

The following elections to fellowships of the Imperial College of Science and Technology have been made : Sir Harold Roxbee Cox, director, Wilmot Breeden (Holdings), Ltd., the Metal Box Company, etc., former special lecturer in aircraft structures; 